\title{
El comercio de Cartagena y Alicante tras la guerra de sucesión
}

\author{
VICENTE Montojo \\ Universidad de Murcia
}

\begin{abstract}
RESUMEN
El objeto de este artículo es el estudio de los grupos mercantiles de Alicante $y$

Cartagena, puertos del Levante español, en los años 1711-1725. A pesar de su proximidad geográfica pertenecían a distintos reinos (Valencia y Murcia respectivamente) y coronas (Aragón y Castilla), pero la composición de estos grupos mercantiles fue muy parecida, desde la proliferación de franceses e ingleses en la $2^{a}$ mitad del XVII hasta el definitivo afrancesamiento de principios del XVIII, e incluso puede destacarse la cooperación a través de compañías de comerciantes de una y otra ciudad.
\end{abstract}

ABSTRACT

The object of this article is the study of the mercantile groups of Alicante and Cartagena, ports of the Spanish Levant, in the years 1711-1725. In spite of his geographical proximity they concerned to different kingdoms (Valencia and Murcia respectively) and you crown (Aragon and Castile), but the composition of these mercantile groups was very similar, from the proliferation of Frenchmen and english men in 2 a half of the XVIIth up to the definitive frenchification of beginning of the $X V I I I t h$, and even one can distinguish the cooperation across merchants' companies from one and another city.

Recibido: 02-07-2010

Aceptado: 04-11-2010 


\section{INTRODUCCIÓN}

El colectivo comerciante de Alicante y Cartagena del reinado de Felipe V, al que nos referimos aquí como grupo social y económico, fue uno de los propulsores del crecimiento económico de los reinos de Valencia y Murcia, al que quizá se ha dado poca importancia ${ }^{1}$, y experimentó un notable cambio dentro de una continuidad, como fue una configuración más plurinacional, pues a la tradicional composición genovesa y francesa, característica del comercio de Levante, y acorde con la alineación de la ciudad de Génova con España ${ }^{2}$, se sumaron otros grupos más o menos numerosos, como irlandeses, suizos, saboyanos y venecianos. Otro aspecto característico del reinado de Felipe $\mathrm{V}$ fue la actitud de resistencia a la presión fiscal que adoptó el conjunto de los comerciantes, lo que les obligó a nombrar diputados por naciones y a que los cónsules tomaran posturas de fuerza contra los nuevos impuestos introducidos por Felipe $\mathrm{V}$, y una última nota característica fue una mayor tendencia a formar compañías mercantiles.

Si su funcionalidad es evidente desde el punto de vista de la historia del arte, como intermediario de imágenes italianas que se hicieron traer $^{3}$, como la Virgen de la Caridad de Cartagena (1723) ${ }^{4}$, o la Virgen de las Maravillas de Cehegín ${ }^{5}$; lo mismo se puede decir en relación a otros productos, pues tanto en Cartagena como en Alicante sus grupos mercantiles continuaron siendo protagonistas de las tradicionales exportaciones lanera y barrillera, así como de importaciones de alimentos y manufacturas, en un contexto político favorable a Francia y a Génova y contrario a Gran Bretaña y Holanda.

Alicante, ciudad portuaria de buen acceso a Madrid, experimentó una recuperación del tráfico mercantil en los primeros años del siglo XVIII6; en cambio en Cartagena, a pesar de su larga tradición mercantil en los dos siglos anteriores, vivió su comercio una situación positiva muy al principio del mismo siglo (1700-1702) ${ }^{7}$

1 Giménez López, E. Alicante en el siglo XVIII: Economía de una ciudad portuaria en el Antiguo Régimen, Valencia, 1981. Por lo que se refiere a Cartagena apenas ha recibido atención, a diferencia del de la $2^{\text {a }}$ mitad del XVIII, salvo por Parrón Salas, C. "Comercio marítimo y comerciantes de Cartagena en el siglo XVIII», en Revista de Historia Naval, 29 (1990), 23-61. Parrón Salas, C. «El tráfico marítimo a través de Cartagena», en Mas García, J. dir. Historia de Cartagena, Murcia, 2000, pp. 189-212.

2 Constantini, C. La Repubblica di Genova nell'età moderna, Turín, 1978. Puncuh, D. ed. Storia di Genova. Mediterraneo, Europa, Atlántico, Génova, 2003.

3 Sáez Vidal, J. «Alicante en el comercio artístico entre España e Italia durante la edad moderna: comitentes, mecenas y artistas», en Exposición La luz de las imágenes: La faz de la eternidad, Alicante, 2006, pp. 73-103.

${ }^{4}$ La trajo de Nápoles el marino Francisco Irsino: Ferrándiz Araujo, C. Magna Cáritas. Arte, cultura y religiosidad en la patrona de Cartagena y su templo, Cartagena, CajaMurcia, 1994.

5 Fue encargada por los franciscanos al comerciante genovés de Cartagena Pedro Antonio Pereti: Moreno Pastor, F. Historia de la Virgen de las Maravillas. Cehegín, 1950 [1748], pp. 4-5.

6 Lo atestigua el derecho de aduana: Salvador Esteban, E. «La 'frontera' intrarregnícola valenciana y su impacto en las instituciones reales. El ejemplo de las dos bailías generales», en Pedralbes, 13 (1993), 11-23.

7 Velasco Hernández, F. «La Sosa-barrilla: una señal de identidad del Campo de Cartagena en los siglos XVI al XIX», en Revista Murciana de Antropología, 10 (2004), 145-158. 
pero, como el de Málaga $^{8}$, entró en crisis poco después, según testimonios de 1706. Don Sebastián del Hoyo Santelices informó sobre el contrabando en la jurisdicción de Cartagena diciendo «no haber habido desde que se principió la guerra descamino, denunciación ni otra cosa que mire a contrabando pues, vigilando con la entereza y fidelidad de montañés a desempeñar la confianza del encargo que la piedad de Su Majestad me ha conferido, no he encontrado en qué ejercer el oficio, hallando viven todos con aquel cuidado y legalidad que deben; verdad es que es el puerto más escaso de comercio éste y la poca ropa que ha entrado la más viene de países de Francia y toda con los despachos y requisitos necesarios que es cuanto puedo sobre este asunto dar cuenta a Vuestra Señoría» ${ }^{9}$. Esta opinión de las autoridades, sin embargo, contrastó con una notable presencia de extranjeros, que eran sobre todo comerciantes, en una proporción superior a la de otras épocas: 79 extranjeros en 1715, de 1.245 vecinos, un 6’3\% (sólo superado en 1634, 78 extranjeros, 6,6\% ${ }^{10}$. Hubo, por lo tanto, un grupo comercial cuya entidad destacó sobre la de su actividad económica. Es una paradoja, salvo que la información con que contaban las autoridades fuera errónea. Se confirma además la permanencia de unas actividades tradicionales: la exportación de lana y barrilla, la importación de pescado salado y la provisión de cereales a Orán y otras poblaciones españolas.

\section{LA SITUACIÓN NACIONAL E INTERNACIONAL EN RELACIÓN AL COMERCIO (1689-1715)}

Los años 1689 a 1702 conllevaron una serie de cambios en el mapa político de Europa, pues Guillermo de Orange lideró el cambio dinástico en Inglaterra, convirtiéndose en rey de esta y estatúder de Holanda, potencias navales que se aliaron en 1701 con Austria con el fin de evitar la sucesión francesa en España, provocando la Guerra de Sucesión ${ }^{11}$. A la Revolución Gloriosa en Inglaterra siguió una política de fuerza protestante en Irlanda (1690) y acompañó la Guerra de la Liga de Augsburgo (1689-1697) contra Luis XIV de Francia, quien anteriormente había tomado medidas contra los protestantes franceses o hugonotes (revocación del Edicto de Nantes en 1685); de todo ello resultó una nueva fase de emigraciones, la de irlandeses a España y Francia y la de hugonotes a Holanda y Prusia, produciéndose así un cambio en el mapa de las comunidades extranjeras. La Guerra de Sucesión de España culminó la alteración en la distribución de las comunidades,

8 Villar García, B. «Las estrategias familiares de la burguesía mercantil en el siglo XVIII. Algunos ejemplos malagueños», en Casey, J./Hernández Franco, J. eds. Familia, parentesco y linaje, Murcia, 1997, pp. 311-321.

9 Archivo Histórico Nacional (AHN), Estado, legajo 287, Cartagena, 19-IV-1706.

10 Torres Sánchez, R. Ciudad y población: El desarrollo demográfico de Cartagena durante la Edad Moderna, Murcia, 1998, p. 278. Este porcentaje corresponde al censo de Campoflorido.

11 Crespo Solana, A. «Guillermo III de Orange y la sucesión de la monarquía hispánica (16891702)», en La sucesión de la monarquía hispánica, 1665-1725, Córdoba, Universidad de Córdoba, 2005, pp. 75-104. 
de tal forma que tanto en Alicante y Cartagena como en Mallorca ${ }^{12}$ fue característico de esta época el afrancesamiento del comercio levantino, frente al predominio genovés e inglés anterior ${ }^{13}$, afrancesamiento propiciado por la sucesión borbónica, pues el alineamiento inglés y holandés contra España en la guerra hizo predominar a los comerciantes franceses, sobre todo a los procedentes de Béarn ${ }^{14}$, y la dirección de las exportaciones de barrilla hacia Marsella, cambios que se dieron asimismo en Navarra ${ }^{15}$, pero junto a ello hubo una continuidad del tráfico con Italia, en lo que incidió la permanencia de genoveses, florentinos y venecianos, o de sus descendientes, y sus buenas relaciones en aquella península ${ }^{16}$.

El tráfico mercantil del Levante español se había visto muy condicionado por la paz y la alianza de España con Inglaterra y Holanda desde 1667-1672 ${ }^{17}$, pero aún en la transición de uno a otro siglo experimentó unos años de paz beneficiosos para su recuperación (1697-1702), en contraste con los de la Guerra de los Nueve Años (1689-1697), lo que se manifestó en un alza tanto de las exportaciones de frutos de la tierra por Alicante, reflejado en la elevación del derecho de aduana, como en la de barrilla por Cartagena. Fue ésta, sin embargo, una situación transitoria, que finalizó con la Guerra de Sucesión española (1702-1715). El Ayuntamiento de Cartagena instauró en 1703 un arbitrio de 3 reales de vellón por arroba de lana lavada y 1'5 por la de sucia que se embarcasen, que dio 6.000 reales y 3.000 reales respectivamente ${ }^{18}$.

Con la paz de Utrecht $(1713)^{19}$ el comercio español perdió oficialmente el monopolio del comercio con América, que siguió centralizado por medio de la Casa de Contratación, primero en Sevilla y después en Cádiz (1717), a causa de nuevas concesiones a Inglaterra: el asiento de negros y el navío de permiso (dos desde 1715). Estas concesiones en materia comercial se dieron anteriormente, pero las de Utrecht, junto con las pérdidas de Gibraltar y Menorca, fueron enormemente

12 Bibiloni Amengual, A. «Intermediarios imprescindibles. Los extranjeros en la élite del comercio mallorquín del siglo XVII: el mercado del aceite», en Villar García, M.B./Pezzi Cristóbal, P. eds. I Coloquio Internacional Los Extranjeros en la España Moderna, Málaga, 2003, I, pp. 203-215.

13 Pérez Aparicio, M.C. «El expansionismo comercial británico en el País Valenciano: el proyecto de creación de puerto franco en Alacant en 1707», en Revista de Historia Moderna, 11 (1992), pp. 251-264. También en Málaga: Santos Arrebola, M. S. «Los hombres de negocios extranjeros en la Málaga del último tercio del siglo XVII», en Villar García, M.B./Pezzi Cristóbal, P. eds. I Coloquio Internacional Los Extranjeros en la España Moderna, Málaga, 2003, t. I, pp. 635-641.

${ }_{14}$ Montojo Montojo, V./Maestre de San Juan Pelegrín, F. «Le Béarn et le Levant espagnol», en Revue de Páu et du Bearn, 32 (2005), 215-228.

15 Azcona Guerra, A. M. Comercio y comerciantes en la Navarra del siglo XVIII, Pamplona, 1996.

16 Fernández de Pinedo, E. «Comercio colonial y semiperiferización de la monarquía hispana en la segunda mitad del siglo XVIII», en Áreas. Revista de Ciencias Sociales (Desigualdad y dependencia. La periferización del Mediterráneo Occidental (s. XII-XIX), 1986, pp. 121-131.

17 Sánchez Belén, J.A. «El comercio de exportación holandés en el Mediterráneo español durante la regencia de doña Mariana de Austria», en Espacio, Tiempo y Forma (Ha Moderna), 9 (1996), 267-321.

18 Cotallo de Aranguren, M.D. Cartagena y el Primer Borbón de España: Guerra de Sucesión (17001715), Murcia, 1982, p. 66. Se trata de cifras muy inferiores a las de 1715-1748 de la aduana: Parrón Salas, C. 2000, p. 201.

19 Kamen, H. La Guerra de Sucesión en España, 1700-1715, Madrid, 1974. 
gravosas para España, que luchó toda la primera mitad del XVIII por suprimirlas, hasta conseguirlo.

Una vez terminado el conflicto sucesorio en Levante (1706-1708), las necesidades fiscales de Felipe $\mathrm{V}$ condujeron a trasladar la aduana de Murcia a Cartagena (1708), con perjuicio para esta ciudad, que vio alterada y más gravada su contribución fiscal. El Ayuntamiento de Cartagena protestó, puesto que a causa de la nueva aduana se quedó sin propios con los que pagar el servicio ordinario y extraordinario, accediendo por ello a una petición de arrendar la sosa de los almarjales. También protestó el de Alicante, que perdió el control de sus antiguos derechos impositivos sobre el comercio ${ }^{20}$.

A ello se añadió la remodelación del mapa aduanero español. Se ha dicho que quedó un territorio nacional más homogéneo, pero no se creó un mercado nacional integrado. Hubo medidas proteccionistas y de fomento: medidas contra Portugal y Francia (contra la última por introducir artículos americanos), instauración del derecho de palmeo, protección del cacao americano y la industria naval española; creación de la Real Compañía Guipuzcoana de Caracas y de la Real Compañía de Galicia ${ }^{21}$; restauración de la Junta de Comercio, etc. No obstante, la política aduanera no dio lugar a un arancel general y a una recopilación hasta finales de siglo XVIII, ni a un arancel realmente proteccionista hasta principios del $\mathrm{XIX}^{22}$, aunque según otros este proteccionismo se haría sentir en Francia ya a finales del siglo anterior ${ }^{23}$.

El mapa de mercados relacionados con el comercio levantino español no sólo acusó esta coyuntura internacional de enfrentamiento entre España y Gran Bretaña, sino otras circunstancias adversas, unas de mayor duración que otras, como la pérdida de Orán ${ }^{24}$, que fue especialmente significativa para Cartagena de Levante, ciudad desde la que era tradicionalmente socorrida y proveída ${ }^{25}$. Además, la Guerra de Sucesión afectó notablemente a los comerciantes de Cartagena, no sólo porque en ella fueran austracistas algunos importantes genoveses ${ }^{26}$, implicados junto con otros mercaderes ${ }^{27}$, sino también porque aún otros se vieron beneficiados

20 Giménez López, E. «Los problemas económicos del siglo XVIII. La acción política del humanista Felipe Bolifón», en Mayans y la Ilustración (Simposio Internacional en el Bicentenario de la muerte de Gregorio Mayans. Valencia-Oliva 30 sept.-2 oct.), Valencia, 1990, t. II, pp. 613-626. [Gregorio Mayans digital].

21 Gárate Ojanguren, M./Blanco Mozos, J.L. «Financiación de las compañías privilegiadas de comercio en la España del siglo XVIII», en Torres Sánchez, R. ed. Capitalismo mercantil en la España del siglo XVIII, Pamplona, 2000, pp. 173-209.

22 Vidal, J.J./Martínez Ruiz, E. Política interior y exterior de los Borbones, Madrid, Istmo, 2001.

23 Desplat, Ch. Pau et le Béarn au XVIIle siècle, Biarritz, 1992, pp. 151-155.

${ }^{24}$ Maestre de San Juan Pelegrín, F. «La caída de Orán en 1708», en Cartagena Histórica, 16 (2006), 14-20.

${ }_{25}$ Montojo Montojo, V./Ruiz lbáñez, J.J. «Relaciones y agentes comerciales entre Orán y el Reino de Murcia en la primera mitad del siglo XVII», en Murgetana, Revista de la Real Academia Alfonso X el Sabio, 120 (2009), 111-127.

26 Muñoz Rodríguez, J.D. «¡Cartagena por el Archiduque Carlos! La sublevación austracista de una ciudad castellana durante la Guerra de Sucesión», en Cartagena Histórica, 16 (2006), 27-43.

27 Como Ginés Osorio, con tienda de especiería: Archivo Histórico Provincial de Murcia (AHPM), Protocolo (Prot.) 2800, 1717, fs. 150-190. 
al poder aprovecharse de las confiscaciones que resultaron de los procesos judiciales contra los tránsfugas ${ }^{28}$. Sin embargo, las guerras del primer reinado de Felipe $\mathrm{V}$, tan perjudiciales para el comercio, dieron lugar a la necesidad de construir una nueva armada, después de la pérdida de la existente en Cabo Passaro (1718), lo que condujo a la creación de los departamentos marítimos, entre ellos el del Mediterráneo (1726) con sede de su capitanía general en Cartagena. Ello tuvo una repercusión mayor para el comercio cartagenero que ciertas reformas hacendísticas, como la restauración de la Superintendencia de Hacienda.

Felipe V, tras su matrimonio con Isabel de Farnesio, luchó durante su primer reinado por recuperar antiguos dominios de Italia (Sicilia y Milán, Nápoles y Cerdeña, que habían sido adjudicados en Utrecht a Saboya y Austria respectivamente), de tal forma que durante el gobierno de Alberoni toda Cerdeña y una gran parte de Sicilia fueron ocupadas por España, expedición que se preparó en Alicante ${ }^{29}$, provocando la intervención de Francia y Gran Bretaña en su contra, enfrentamiento que terminó con la cesión de Cerdeña a Saboya y de Sicilia a Austria. Por otra parte, España perdió definitivamente el Milanesado en 1713, que pasó también a Austria ${ }^{30}$.

El tráfico de España con Italia se resintió especialmente en este periodo. Génova no mantuvo su importancia política y sufrió la competencia de Marsella en Francia, puerto al que llegaban los lienzos de Lyon, «fabricados en su mayor parte en Alemania» según el cónsul francés de Alicante ${ }^{31}$. Con la inmigración francesa, el comercio de Levante experimentó la incorporación a su tráfico de la ruta del Mediterráneo Oriental (Esmirna).

La necesidad de la lucha en el mar, por una parte, dio lugar en época posterior a la formación de una armada propia, nacional ${ }^{32}$, a la que aún contribuyó la flota de galeras por asiento con los genoveses (recuérdese a los Doria), aprovisionada a veces desde Alicante.

La pérdida de Orán como consecuencia de la traición del conde de Santa Cruz de los Manueles, cuatralbo de las galeras de España, quien abrió las puertas de Cartagena a los aliados, tuvo asimismo incidencia directa para el comercio de Cartagena. En medio de las operaciones militares de la Guerra de Sucesión, además de Gibraltar y Menorca, también Orán fue perdida por las tropas borbónicas. Se trataba de una plaza militar muy relacionada con Alicante y sobre todo con Cartagena, puesto que desde ella era proveída del sueldo y bastimentos para la guarnición.

\footnotetext{
${ }^{28}$ Los franceses Lázaro Conte y Pedro Rey en Cartagena.

29 Alberola Romá, A. «En torno a la política revisionista de Felipe V: los fletamentos de buques extranjeros en el puerto de Alicante y su empleo en la expedición a Sicilia del año 1718», en Revista de Historia Moderna, 10 (1991), 263-285.

30 Vidal, J.J./Martínez Ruiz, E. 2001, pp. 61-64 y 232-236.

31 Kamen, H. La España de Carlos II, Barcelona, Crítica, 1981, p. 187.

32 En ello tuvo mucho que ver la instalación de uno de los departamentos marítimos en Cartagena a partir de 1726. Posteriormente se construyó el Arsenal de Marina (1748-1784): Merino Navarro, J.P. «El Arsenal del Mediterráneo español», en Áreas, 1 (1982), 41-52.
} 
En conclusión, si la guerra tuvo una gran influencia en el comercio, también lo hizo la política exterior de la monarquía, que no olvidemos que fue fundamentalmente dinástica y no nacional durante todo el siglo XVIII ${ }^{33}$.

No obstante, un elemento positivo de esta época fue el crecimiento demográfico. Tanto en el reino de Murcia como en el de Valencia el saldo vegetativo fue positivo en dicho periodo ${ }^{34}$. En Cartagena este crecimiento tuvo un comienzo temprano (finales del XVII), de marcado carácter rural, aunque con una relativa atonía en la primera década del XVIII, se reanudó después, acentuándose a mediados del mismo, ya de carácter urbano. El crecimiento demográfico fue un impulso fuerte para el comercio de Cartagena. Se dio además un periodo de ausencia de grandes epidemias, por lo menos en la primera mitad del XVIII, en la que sólo hay que señalar la amenaza de la peste de Marsella, que no llegó a afectar a la población ${ }^{35}$.

La sociedad cartagenera evolucionó hacia una mayor proporción de población rural que urbana a finales del XVII y principios del XVIII, hecho que permitió un mayor nivel de economía de subsistencia, característica que no implicó un abandono del comercio, pues la producción agropecuaria (trigo, cebada, barrilla, lana) fue destinada en gran parte al comercio, a pesar de que esta actividad se vio muy limitada a causa de las numerosas guerras en que España participó, como también de las malas cosechas ${ }^{36}$ y de los naufragios de navíos, como el genovés La Esperanza en $1726^{37}$.

Los comerciantes de Alicante y Cartagena canalizaron la salida de productos agrarios del campo propio (no exclusivamente, también los de otras zonas), pero surtieron también a la ciudad de otros productos que necesitaba, de todo tipo (alimenticios y manufacturas). Una población como la de Cartagena, en crecimiento y de composición plural (urbana y rural), hubo de generar lógicamente un volumen y una variedad de negocios determinados, que no podemos cuantificar por falta de estadísticas.

Alicante, que apuntaba una evolución demográfica parecida a la de Cartagena, acusó más su paralización con el bombardeo de 1691 y los posteriores de 1706 y 1708 , pero experimentó una pronta recuperación a partir de $1710^{38}$.

De alguna manera podemos hablar de un comercio exterior mayorista (importación, exportación y reexportación), de otro interior también mayorista (abastecimiento local estancado por el Ayuntamiento, suministros de ámbito local, comarcal

${ }^{33}$ Hernández Franco, J. Aspectos de la política exterior de España en la época de Floridablanca, Murcia, 1992.

${ }^{34}$ Bustelo García del Real, F. «El vecindario general de España de 1712-1717 o Censo de Campoflorido», en Revista Internacional de Sociología, 7-8 (1973), 83-103 y 8-35.

35 Torres Sánchez, R. 1998, pp. 97-107. Salvo una epidemia en 1708 producida por las tropas.

36 Puede ser ilustrativo el ejemplo de la espera que Schirmer y compañía y otros dieron a Juan Saborni: AHPM, Prot. 5767, fs. 71-73, 10-5-1724.

37 AHPM, Prot. 5977, fs. 207r-208v, 31-7-1726; y Prot. 6008, f. 222, 25-5-1726.

38 Pradells Nadal, J. Del foralismo al centralismo (Alicante, 1700-1725), Alicante, 1984. 
y regional), y de un comercio minorista. El comercio exterior estuvo casi siempre vinculado a las relaciones diplomáticas, de tal forma que la ruptura de estas últimas supuso la interrupción del comercio. Con la instauración de una nueva dinastía, la de los Borbones se zanjó el característico enfrentamiento con Francia del reinado de Carlos II (salvo en 1718-1721) y se incrementaron o recuperaron las relaciones comerciales con las zonas francesas con las que antiguamente había más contacto: Bretaña (productora de lienzos y suministradora de pescado) y el Mediodía, principalmente a través de Marsella, como también con el norte de Italia a través de Génova y Venecia, según una tradición de siglos anteriores ${ }^{39}$.

\section{FRANCESES E IRLANDESES EN EL COMERCIO DE ALICANTE TRAS LA GUERRA DE SUCESIÓN (1715-1746)}

Francisco Marabeuf y Nicolás Rosa, franceses, uno bretón y el otro marsellés, o Cristóbal Hall, irlandés, sirven de ejemplos de comerciantes de Alicante de la época de la Guerra de Sucesión de España y posterior, en la que se consolidó la presencia de inmigrantes procedentes de estos territorios citados, que se había iniciado desde 1697, en que España había dejado de estar en guerra con Francia. Como el reinado anterior de Carlos II, el de Felipe V (1700-1746) fue una etapa de numerosas guerras, sobre todo con Inglaterra y Holanda, por lo que las dificultades para el tráfico mercantil fueron muchas. En consecuencia, se dieron unas condiciones peculiares entre las que cabe destacar la participación de algunos comerciantes en actividades militares o de intendencia. La preparación de expediciones armadas con destino a Italia u Orán dio ocasión a tal intervención de los comerciantes en los suministros militares, que fueron una de las actividades más lucrativas de entonces y en la que intervino Marabeuf ${ }^{40}$.

El comercio de Alicante, al que nos referimos aquí como colectivo y no como tráfico, sigue suscitando interés en los últimos años, como puede deducirse de las publicaciones que siguen saliendo, aunque referidas casi todas al siglo $\mathrm{XVII}$, con alguna excepción ${ }^{42}$, por lo que constituye un objeto de investigación frecuente en la historiografía. De modo excepcional, este comercio no dio lugar a un consulado, ni se aglutinó en una entidad, como también sucedió en Cartagena, sino que se compuso de diversos grupos de grandes y medianos comerciantes, muchos de ellos extranjeros, que contaron con sus cónsules extraterritoriales y sus diputados, pero también naturales o valencianos. Los hombres de negocios estuvieron re-

39 Velasco Hernández, F. Auge y estancamiento de un enclave mercantil en la periferia. El nuevo resurgir de Cartagena entre 1540 y 1676, Murcia, 2001.

40 Archivo Histórico Provincial de Alicante (AHPA), Prot. 790, fs. 396-397, 24-9-1724.

41 Blanes Andrés, R. «El comercio marítimo de Alicante hacia Valencia en el segundo cuarto del Seiscientos (1626-1650)», en Revista de Historia Moderna, 26 (2008), 275-302. Martínez Ruiz, J.I./Gauci, P. Mercaderes ingleses en Alicante en el siglo XVII, Alicante, 2008.

42 Montojo Montojo, V. «Los comerciantes de Alicante y Cartagena en la Guerra de Sucesión», en Estudis. Revista de Historia Moderna, 34 (2008.), 219-240. 
presentados por algunos de ellos en los ayuntamientos, aunque de forma muy minoritaria; y también en las instituciones territoriales, como la Intendencia del Reino y sobre todo en la Provisión de víveres, de carácter militar, en la que fueron mucho más importantes. Su colaboración en esta entidad de intendencia militar y en la recaudación de rentas fiscales se hizo muy importante al final de la Guerra de Sucesión, en la época de dominio borbónico (desde 1708-1709) ${ }^{43}$, pero lo fue conflictiva, pues la introducción de una nueva fiscalidad de tipo castellano por Felipe $\mathrm{V}$ y sus oficiales y sobre todo la reforma aduanera (elevación de las rentas de aduanas y utilización de nuevas técnicas de control del contrabando) dio lugar a una gran oposición de los comerciantes ${ }^{44}$.

En 1716, por ejemplo, la Junta de Dependencias y Negocios de Extranjeros recibió varios memoriales de los comerciantes franceses de Alicante y Cartagena en razón de los alojamientos de soldados a que les obligaron, o de los cónsules por otros motivos ${ }^{45}$.

A pesar de estos problemas de tipo fiscal, hay que destacar la reconstitución de los grupos que formaban el comercio de Alicante, como los de valencianos, ingleses, genoveses y franceses, todo ello a veces en un contexto de intercambio, como en la acción de los diputados de las distintas naciones o en sus relaciones familiares.

Una primera parte de los documentos municipales de Alicante hace referencia a los problemas de los años 1711-1713, como la presión fiscal y la nueva práctica contra el contrabando, pero muy pronto surgió la oposición de los cónsules y diputados de las naciones, también de la española.

En ellos figuran Francisco Marbeuf, Nicolás Rosa ${ }^{46}$, Pedro Lombardón, Francisco $\mathrm{Nas}^{47}$ y otros franceses, formando compañías de unos pocos socios, en general comisionistas de negociantes de Marsella, muy relacionados también con los de Valencia ${ }^{48}$.

43 Pradells Nadal, J. Del foralismo al centralismo (Alicante, 1700-1725), Alicante, 1984.

44 Giménez López, E. «Los problemas económicos del siglo XVIII. La acción política del humanista Felipe Bolifón», en Mayans y la Ilustración (Simposio Internacional en el Bicentenario de la muerte de Gregorio Mayans. Valencia-Oliva 30 sept.-2 oct.), Valencia, 1990, t. II, pp. 613-626. [Gregorio Mayans digital].

45 AHN, Estado, legajo 610, expedientes 34 (soldados), 36 (derechos consulares) y 53 (acopios de sal).

46 Nicolás Rosa, negociante de Alicante, hizo provisión de caudal para liquidar las deudas de Antonio Dupín, su socio, entre cuyos acreedores estaban Bartolomé Odo, mr. Casart, Tomás Laugier y Claudio Rosa, de Marsella, Amiel y Fusati, de Cartagena, y Abraham Tabues, de Dublín: AHPA, Prot. 61, fs. 71-75, 11-9-1714.

47 En 1710 daban poder como diputados de la nación francesa a Francisco Desables y Beltrán Pascal, franceses de Madrid, para protestar de las novedades de Felipe Bolifón: AHPA, Prot. 441, f. 38, 8-41710.

48 Franch Benavent, R. «Negocios y clientelismo político: los mecanismos de movilidad social en la burguesía valenciana del siglo XVIII», en Territorios distantes, comportamientos similares. Familias, redes y reproducción social en la Monarquía Hispánica (siglos XIV-XIX), Murcia, 2009, pp. 113-151. 
El comercio francés, en el sentido de colectivo o grupo, se formó o arraigó en el propio reinado de Carlos II (1665-1700), en lo que se refiere a los siglos XVIIXVIII ${ }^{49}$, a pesar de cuatro guerras contra Luis XIV (1667-1697). De ello pueden servir de ejemplo los comerciantes Jaques Llop, marsellés, Juan Vinyau, Tomás Subiela, Pedro Lostau y Juan Bautista Lostau, bearneses, y Francisco Marbeuf, bretón, que representaron a los grupos más característicos del comercio francés de Alicante, muy relacionados en Marsella.

Llop se introdujo en una interesante red mercantil, pues casó con una mujer de la poderosa comunidad genovesa de Alicante (Francisca Bojoni) ${ }^{50}$ y contó con un hermano (Bartolomé Llop o Loup) en Puerto de Santa María y clientes en Mallorca, como el nizardo Ramón Lanteri, residente en Palma hasta 1673, que contó con él para asuntos relacionados con Juan Bautista Corsiniani, florentino establecido en Alicante ${ }^{51}$.

En los años 1711-1725 fueron muchos más los franceses que comerciaron en Alicante, de cuya actividad puede destacarse la exportación de frutos del país (almendra, anís, barrilla, lana, sal), la importación de géneros ultramarinos y la venta al fiado, por medio de obligaciones de pago, dirigida a pequeños comerciantes o botigueros, como también a habitantes de pueblos vecinos de las gobernaciones de Orihuela y Játiva, y del reino de Murcia (Algezares, Cieza, Murcia, Yecla, Hellín, Tobarra, Minaya), donde consiguieron muchos clientes según puede observarse por las obligaciones y poderes otorgados ${ }^{52}$.

\section{LOS COMERCIANTES DE CARTAGENA}

El comercio de Cartagena hubo de afrontar desde principios del siglo XVIII un problema que se agravó a lo largo de todo el reinado de Felipe $\mathrm{V}$, como fue la elevación de la fiscalidad sobre el tráfico, con motivo de la guerra, y que la instauración de la aduana hizo incluso más vejatorio por la instauración del derecho de palmeo. De aquí que las comunidades extranjeras nombraran diputados de sus naciones para pedir que se derogara la nueva fiscalidad, actuación que hicieron conjuntamente por naciones.

En los primeros años del siglo XVIII se reconstituyeron las comunidades mercantiles de Cartagena, como la genovesa, la veneciana y sobre todo la francesa,

49 Aunque con precedentes de finales del XVI: Girard, A. Le Comerse français à Séville et Cádiz au temps des Habsbourgs. Contribution à l'étude du commerce étranger en Espagne aux XVI et XVII siècle, París-Burdeos, 1934, p. 128.

50 Casó también con Diamante Briosco y obtuvo el privilegio de milicia con voto en cortes en 1682: Arqués, A. Nobiliario Alicantino, Alicante, 1966 [1678/1794], p. 57.

51 Bibiloni Amengual, Andreu, El comerç exterior de Mallorca (Homes, mercats i productes d'intercanvi. 1650-1720), Palma, 1990, p. 214. Bustos Rodríguez, Manuel. Un comerciante saboyano en el Cádiz de Carlos II (Las memorias de Raimundo de Lantery, 1673-1700), Cádiz, 1983, pp. 111-2.

52 Obligaciones de Yecla: AHPA, Prot. 2217, f. 121, 1719; 625, f. 55, 1723; y 630, f. 379, 1728. 
como lo hacían también en otras ciudades portuarias, como Cádiz ${ }^{53}$ y Málaga ${ }^{54}$. Sin embargo, lo hacían en distinto número en estas ciudades, pues mientras en Alicante había 108 comerciantes hacia 1730, en Cartagena no llegaban al medio centenar.

Los comerciantes hubieron de restablecer sus redes familiares, cuyos negocios no se limitaron a una u otra ciudad, sino que les unieron a las de ambas y además con las de Valencia, Granada o Madrid. Esta relación más o menos estrecha entre comerciantes de Cartagena y Alicante no excluye que se hubiera dado competencia entre las autoridades portuarias, acusándose en Cartagena a fines del XVII a los recaudadores de Albacete y Murcia por perjudicarla en beneficio de Alicante ${ }^{55}$.

El entramado familiar de las redes mercantiles ${ }^{56}$, organizadas por medio de compañías, se manifestó en que algunas estaban formadas por hermanos o socios distribuidos en una y otra ciudad. Salía a relucir en el momento de la muerte de alguno de los asociados, como Antonio Pavía, de Alicante, en relación a Carlos María Rizo, negociante de Cartagena, su socio ${ }^{57}$. Era una estrategia profesional de gran tradición entre los comerciantes, que se mantuvo en los siglos XVI a XVIII y que se encauzó frecuentemente mediante vínculos familiares. Los hermanos Chereguini, por ejemplo, formaron una compañía: Julio Antonio Chereguini, cónsul de Génova en Cartagena, y José Chereguini en Valencia ${ }^{58}$. Entre los mercaderes de vara y los extranjeros abundaron estas relaciones: en Cartagena Damián Valentín, mercader de vara, estuvo casado con Magdalena Bolmás, hija de José Bolmás, también mercader de vara, y varios de los comerciantes franceses de esta época (Román, Soler) estuvieron casados con las hermanas Jiménez de Cisneros.

\section{Los españoles}

Hubo además en Cartagena unos pocos mercaderes nacionales o naturales de España, tanto de Cartagena (Francisco Castañeda, Blas Martínez Fortún, Juan y

${ }^{53}$ Bustos Rodríguez, M. «La burguesía mercantil en el Cádiz del siglo XVII: proceso de formación y estructura», en Congreso Internacional La Burguesía española en el Antiguo Régimen (Madrid, 1991), Valladolid, 1996, pp. 1233-1265.

${ }_{54}$ Quintana Toret, F.J. «La crisis del comercio malagueño en la transición del siglo XVII al XVIII», en Baetica, 4 (1984), 279-289. Villar García, M.B. Los extranjeros en Málaga en el siglo XVIII, Córdoba, 1982. Idem. «Comercio y comerciantes en Málaga a principios del siglo XVIII: D. Francisco de Cárdenas», en Lobo Cabrera, M./Suárez Grimón, V. eds. El comercio en el Antiguo Régimen (III Reunión Científica de la Asociación Española de Historia Moderna), Las Palmas, 1994, II, pp. 127-137.

${ }_{55}$ Montojo, V./Maestre de San Juan Pelegrín, F. «La actividad de los mercaderes de Cartagena en el Reino de Granada a finales del siglo XVII», en El Reino de Granada en el siglo XVII, Almería, 2000, pp. 111-120, cfr. 112, nota 6.

56 Azcona Guerra, A.M. «Pautas de análisis de la estructura familiar del negocio comercial navarro en el siglo XVIII» y Pérez Hervás, J./Pérez Ortiz, A.L. «Estructura familiar y condición social de la población francesa en Murcia (siglo XVIII)», en Chacón Jiménez, F./Ferrer i Alós, LI. eds. Familia, casa y trabajo, Murcia, 1997, pp. 345-370 y 297-312.

57 Poder de Carlos Mํㅡㄹ Rizo a Luis Lombardón: AHPM, Prot. 5518, f. 223, 12-4-1723.

58 Arrendamiento de un mesón a Antonio Tarrida, francés: AHPM, Prot. 5714, f. 53, 2-4-1728. 
Francisco González, Mateo González López del Castillo, Juan Navarro, Alonso Oviedo, Alonso Rodríguez de Rionegro, Damián Valentín, Juan Villalva), como de otras poblaciones murcianas (José Yúfera, de Totana) y de otros reinos castellanos: Nicolás de Borja y Vivar (Antequera, Málaga), Mateo García Bustamante (Campuzano, Burgos); como también de Cataluña: Nicolás Toya Monserrate, José Bolmás, Francisco y José Bonet, José Caldes; Juan y José Llobregat; Valencia (Vicente Calatayud, de Bocairente), Alicante (Vicente Fajardo) y Menorca (Bernardo Anrrich). Entre los primeros, Alonso Oviedo enriqueció con sus negocios y a principios del XVIII su hijo ennobleció, aunque mantuvo algunos negocios ${ }^{59}$.

\section{Los genoveses}

Predominaban sobre todo en Cartagena algunos comerciantes ya naturalizados de origen genovés, instalados en la ciudad a lo largo del siglo XVII: Domingo Fava, Pantaleón Lardón, Juan Bautista Montanaro; Hércules, Juan Antonio y Miguel Peragalo, Marcos Pereti, Esteban Lamberto, Mateo Rizo, Juan Bautista Tacón.

Iniciada la ofensiva aliada contra España y Francia, Cartagena fue tomada en 1706 por los ingleses, o hablando propiamente fue entregada por algunos españoles, como el conde de Santa Cruz de los Manueles, cuadralbo de las Galeras de España, que residía en Cartagena por su cargo, y otros austracistas ${ }^{60}$, como algunos regidores (Luis Panés) y comerciantes de origen genovés, como Juan Bautista Montanaro, uno de los genoveses que mayor actividad había tenido en las tres últimas décadas del XVII, Antonio María Montanaro, su hijo; Hércules Peragalo, o Nicolás Fábrega, que se pusieron de parte del Archiduque Carlos de Austria. Cabe pensar, por lo tanto, en que la posición austracista de algunos comerciantes genoveses de Cartagena fuera una actitud contrapuesta a la de los franceses llegados en los años anteriores.

Los genoveses Juan Bautista y Antonio María Montanaro tuvieron gran comercio de exportación e importación desde Cartagena con Italia y Holanda ${ }^{61}$, con productos de los reinos de Murcia y Granada. De esta compañía comercial formó también parte su hijo Nicolás Montanaro y estuvo muy activa fundamentalmente en el reinado de Carlos II, muy difícil a causa de las guerras con Portugal y con Francia, con las consiguientes dificultades financieras, desapareciendo entonces la compañía de Agustín Ignacio Prebe y Ansaldo Piquinoti62; la epidemia de peste de $1678^{63}$, la devaluación monetaria y la consiguiente crisis comercial, pero se remontó durante los primeros años del XVIII.

59 AHPM, Prot. 5997, f. 130, 25-4-1703.

60 Cotallo de Aranguren, M.D. op. cit.

61 Montojo Montojo, V./Maestre de San Juan Pelegrín, F. «La actividad...», op. cit.

62 Montojo Montojo, V./Maestre de San Juan Pelegrín, F. «La actividad...», op. cit., p. 111.

${ }^{63}$ Casal Martínez, F. «Dos epidemias de peste bubónica en Cartagena en el siglo XVII (16481676) y una terrible de paludismo en 1785», en Murgetana, 3 (1951), 67-164. 
A pesar de la actitud de algunos genoveses (Montanaros, Fábregas, Peragalos, Antonio Bosomo y Clara Mucio, su madre) y de que se celebró en la ciudad de Génova el pacto de 1705 entre catalanes y el Archiduque Carlos de Austria, otros regidores (Jacinto Antonio Digueri, Francisco Montenegro) y comerciantes de origen genovés (Esteban Lamberto, Nicolás Montanaro ${ }^{64}$, Juan Bta. Pereti, Ángel Rizo) no se alinearon con los austracistas y su presencia continuó siendo muy importante hasta el punto de que el Ayuntamiento dependió financieramente de ellos, como en el caso de los Lamberto, Pereti y Rizo.

El hecho de que Esteban Lamberto mantuviera actividad comercial pasada la Guerra de Sucesión es algo que no nos sorprende, aunque indique la sucesión de varias generaciones de Lambertos en el comercio cartagenero. Los primeros fueron Juan Bautista Lamberto, un artesano que procedente de Génova hacia 1600 llegó a ser hombre de negocios y cónsul de la nación francesa y de las naciones extranjeras, bajo el valimiento del Conde Duque; y Esteban Lamberto, que ejerció también el comercio hasta 1665, continuándolo Agustín y Esteban Lamberto Micol, sus hijos, el primero vecino de Cartagena, quien intervino muy activamente en el comercio con Orán, cuando fueron expulsados los judíos del presidio norteafricano e instalada la base de las galeras de España en Cartagena, intentando cobrar las deudas que con él había contraído el capitán general de Orán y Mazalquivir, para lo que recurría precisamente a los servicios de Esteban Lamberto Micol, su hermano, residente entonces en Orán ${ }^{65}$.

Aunque venía de antiguo, el hecho es que Cartagena contaba en los primeros años del XVIII con un destacado grupo de comerciantes genoveses, importante no tanto por su número, inferior al grupo francés, sino por su volumen de negocios ${ }^{66}$.

Al acabar la guerra los franceses constituían el grupo mayoritario entre los extranjeros instalados en Cartagena ${ }^{67}$ (así se manifestó en el padrón de 1713), pero esto no significa que anularan totalmente a los genoveses: de hecho fue tras la Guerra de Sucesión española cuando se inició de la actividad de 2 importantes comerciantes genoveses. Uno fue Carlos María Rizo, que instalado primero en Alicante sustituyó en Cartagena a Ángel Rizo, su hermano ${ }^{68}$, continuando su actividad toda la primera mitad del siglo. Fue mayordomo del Convento de la Purísima Concepción y San Jorge, de patronato genovés, y diputado de la nación genovesa

64 AHPM, Prot. 5773, f. 437, 4-12-1706.

65 Ruiz Ibáñez, J.J./Montojo Montojo, V., Entre el lucro y la defensa: Las relaciones entre la Monarquía y la sociedad mercantil cartagenera (comerciantes y corsarios en el siglo XVII). Murcia, 1998, pp. 5758.

66 Torres Sánchez, R. «La colonia genovesa en Cartagena durante la Edad Moderna», en Rapporti Génova-Mediterraneo-Atlantico nell' età moderna, Génova, 1990, pp. 553-581, cfr. 567. Román Cervantes, C. «Actividad mercantil en una ciudad de la periferia: Cartagena (1713-1715)», en Cuadernos de Historia Moderna y Contemporánea, 10 (1989-1990), 65-80, cfr. 71.

67 Torres Sánchez, R. «La colonia genovesa...», op. cit., p. 567.

68 Archivo Municipal de Cartagena (AMC), Ac.Cap. 7-10-1713. Fue apoderado de Sebastián Noly, negociante de Alicante: AHPA, Prot. 790, 25-9-1724. 
en Cartagena, junto con Pedro Antonio Pereti, factor de las Galeras de España, que se había dedicado al comercio, como también Juan Bautista Pereti69.

El otro fue Julio Antonio Chereguini, cónsul de Génova, quien declaró ser noble en su ciudad de origen y murió arruinado. Había casado en Génova con Antonia Carminati, de una familia vinculada anteriormente al comercio con Cartagena. Tuvo un único hijo varón, Andrés Chereguini, oficial de la Contaduría de Marina.

Otros comerciantes genoveses de esta época fueron Juan Bautista Barrabino, Pedro Bregante, Juan Bautista Pesceto y Juan Bautista Valarino, este último especiero.

\section{Los franceses}

El predominio de los genoveses, que se daba en otras ciudades portuarias como Cádiz ${ }^{70}$, se trastocó con la Guerra de Sucesión, en beneficio de los franceses $^{71}$, y quizá pudiera señalarse como principal característica del comercio cartagenero su afrancesamiento (entiéndase no en su acepción decimonónica), en contraste con la italianización de las dos centurias anteriores. Pero no se piense que la irrupción y prosperidad del grupo francés, con continuidad a lo largo del XVIII, desbancó a los genoveses, pues éstos recuperaron pronto su importancia cualitativa, aunque no cuantitativa, que fue ensombrecida por los franceses.

Los franceses que se avecindaron en Cartagena a partir de 1660 eran de procedencia distinta o más variada (el sur de Francia) que los de finales del XVI, aunque fuera precaria al principio a causa de la guerras de la Devolución y Holanda: Donato Domás, Pedro Maurel, Antonio Garín, Francisco de Laas (Bearne), César Mirandol (Maus, San Flor, Ubernia), o Antonio Dorz (Marsella).

Desde principios del siglo XVIII predominaron los de las regiones mediterráneas de Rosellón (Diego Román, de Arlés), Provenza (Juan Bautista Bertrandi, de Petres) y Languedoc (Honorato Sairas, de Montpellier; Luis Dhoins, de Caonas, Narbona), y de la más interior del Macizo Central (Auvernia); y un grupo de bearneses de Olorón (Jaime, Francisco y José Soler Espiauba, Juan Palás, Miguel Turón, Pedro Puyou, Pedro Verges, José Casal, o Agustín Poey) ${ }^{72}$ y otras poblaciones cercanas (Santa María, Momour), de Gascuña, y de otras procedencias

\footnotetext{
69 Carta de Patricio Misset a Belluga: Archivo Municipal de Murcia, legajo 2768, Cartagena, 31-8-1707.

70 Lario de Oñate, M.C. La colonia mercantil británica e irlandesa en Cádiz a finales del siglo XVIII, Cádiz, 2000, p. 31.

71 Lemeunier, G. y Pérez Picazo, Mํㅡ T. «Les français en Murcie sous l'Ancien Règime (v. 1700-v. 1850). Des migrations populaires au grand comerse", en Les français en Espagne a l'epoque moderne (XVI-XVIII siècles), París, 1990, p. 111-138.

72 Los bearneses predominaron como inmigrantes no sólo en el Mediterráneo, sino también en otras zonas, como Ferrol en Galicia: Martín García, A. «La colectividad francesa en el Ferrol del siglo XVIII», en Villar García, M.B./Pezzi Cristóbal, P. eds. I Coloquio Internacional Los Extranjeros en la España Moderna, Málaga, 2003, I, pp. 469-480.
} 
más diseminadas, como Antonio Fornalz (Poette Labal, Final), cónsul de su nación; o de Marsella (Noel Bartholón, Claudio Brunet ${ }^{73}$, Lázaro Comte, Antonio y Francisco Despuechs, Bartolomé Fort, asociado a Luis Dhoins ${ }^{74}$; Nicolás Amiel, Agustín Fusati, Jacome Grondona, Juan Laugier, Juan y Pedro Olivier, Juan Bautista Rebufat, Pedro Rey, Juan Bautista Rivier, Juan Saborni ${ }^{75}$ ).

El grupo de bearneses tenía su principal lugar de origen en la industriosa villa de Olorón, impulsora de la fabricación de varios tipos de paños, hechos con lanas procedentes del norte de España (Navarra, Vascongadas), y de un activo comercio con Bayona ${ }^{76}$, La Rochela y el Poitou, en cuyas ferias adquirían telas de Laval ${ }^{77}$ y Maine (navales, humainas, olonas), que enlazaba a compradores españoles con los productores del Oeste francés, obteniendo de las ferias de la misma zona (Niort, Fontenay le Conte, Parthenay), que eran de cambios, los instrumentos de crédito adecuados. No obstante, el radio de acción del comercio de los paños bearneses se reducía a 15-20 kms. en el s. XVIII78. El Golfo de Gascuña había sido, de hecho, a finales de la Edad Media y principios de la Edad Moderna, una zona muy activa (pesca, comercio) de intermediación entre Francia, los Paises Bajos y España ${ }^{79}$, y aunque se vio muy mermada desde mediados del XVI, aún se mantuvo en el XVIII ${ }^{80}$.

El embajador de Francia pidió a Felipe V, al iniciar su reinado, que se nombrasen cónsules de Francia en Málaga, Cartagena y Denia, propuesta que fue aceptada, designándose en Cartagena a Pablo Mirasol como vicecónsul, a petición del cónsul de Alicante, José Baile ${ }^{81}$, pero no duró mucho, pues tras la recuperación de Cartagena por Felipe V lo fueron José Domás Gris, Antonio Fornalz y Juan Bautista Marconie.

Por entonces el Ayuntamiento de Cartagena ponía trabas a la introducción de pieles de carnero por Diego Román ${ }^{82}$, lo que quizá pudiera relacionarse con la competencia entre genoveses y franceses en los primeros años del XVIII, que fueron muy difíciles. Según carta del marqués de Cábrega, gobernador de Cartagena, a Antonio Ibáñez de Bustamante, «los continuados años de la falta de comercio tie-

73 Quizá hermano de Luis Brunet, hombre de negocios en Alicante: Vilar, J.B. Orihuela, una ciudad valenciana en la España moderna, Orihuela, 1981, vol. 2, p. 584.

74 AHPM, Prot. 5521, fs. 522-524, 20-10-1734.

75 Montojo Montojo, V./Maestre de San Juan Pelegrín, F. «Relaciones sociales y actividades económicas de los comerciantes procedentes de los Pirineos franceses en Cartagena (España) a lo largo del siglo XVIII», en Circulación de las mercancías y redes comerciales en los Pirineos, siglos XIII-XIX (Coloquio, Andorra la Vella, 1-4.10.2003), Toulouse, 2005, pp. 191-211, cfr. anexo 2.

76 Desplat, Ch. Pau et le Bearn..., op. cit., p. 27.

77 Pérez Ortiz, A.L. Trayectoria hacia el ocaso (Familia y comercio en Lorca en la transición del Antiguo Régimen a la Edad Contemporánea. Don Antonio Martín Vidal 1767-1826), Murcia, 2003, p. 57.

78 Desplat, Ch. Pau et le Bearn..., op. cit., p. 31.

79 Priotti, J.-P. Bilbao et le commerce européen (vers 1520-vers 1620), Lille, 2002.

80 Poussou, J.P. Bordeaux et le Sud-Ouest au XVIIle siècle. Croissance écononique et attraction urbaine, París, 1983.

${ }_{81}$ AHN, Estado (E), legajo 611, documento n. 5, consulta n. 85.

82 AMC, Ac.Cap. 7-3-1702. 
ne muy pobres a estos caballeros (los regidores del Ayuntamiento de Cartagena) y los pocos acomodados dificultosamente se inclinan a las militares fatigas ...». De este texto se puede deducir que la última guerra con Francia (1689-1697) afectó enormemente al comercio cartagenero, provocando una gran disminución.

Abundando en estos mismos procesos (reducción y afrancesamiento del comercio cartagenero a lo largo de la Guerra de Sucesión borbónica), más clarificador es la siguiente declaración de Sebastián del Hoyo Santelices, informando sobre el contrabando en la jurisdicción de Cartagena: «no haber habido desde que se principió la guerra descamino, denunciación, ni otra cosa que mire a contrabando, pues, vigilando con la entereza y fidelidad de montañés a desempeñar la confianza de la piedad que Su Majestad me ha conferido, no he encontrado en qué ejercer el oficio, hallando viven todos con aquel cuidado y legalidad que deben, verdad es que es el puerto más escaso de comercio éste y la poca ropa que ha entrado la más viene de países de Francia y toda con los despachos y requisitos necesarios, que es cuanto puedo sobre este asunto dar cuenta a Vuestra Señoría».

Algo parecido se puede relacionar con la acción de Patricio Misset, nombrado teniente del rey en Cartagena (cargo que vino a sustituir al de castellano o alcaide de la Fortaleza de Cartagena), tras la expulsión de los ingleses, pues según carta del obispo Belluga a José Grimaldo: «También convendrá mucho (que) Su Majestad le mande que no innove en nada en la práctica que hay en este puerto en cuanto a la embarcación de mercantines que vienen a él, porque les quiere precisar a que los embarcos y desembarcos los hagan con las barcas del puerto y no con las propias, siendo lo contrario lo que siempre se ha practicado aquí, pues en un navío genovés que llegó la semana pasada lo quiso practicar y el cónsul de Génova me trajo un memorial muy fuerte, diciéndome que no vendría nave genovesa a este puerto con el tratamiento que les hacía, y fue menester decirle (que) daría cuenta a Su Majestad para que entrase en dejar correr la práctica que hasta aquí ha visto» ${ }^{83}$.

La ocupación británica de Cartagena hizo sufrir embargos de navíos a patrones genovese ${ }^{84}$ y a los franceses huir y padecer diversas confiscaciones de bienes (entre ellos géneros remitidos desde el extranjero), por lo que litigaron para recuperarlos ante diversas instancias (juez conservador de la nación francesa ${ }^{85}$, Tribunal de la Conservaduría de la nación francesa ${ }^{86}$ y Junta de Dependencias y Negocios de Franceses), una vez que la ciudad fue sometida por las tropas borbónicas.

La actividad de Diego Román nos podría servir de ejemplo de la introducción

${ }^{83}$ Cartas datadas en Cartagena a 8-IV-1706, 19-IV-1706 y 31-X-1707: AHN, Estado, leg. 287 y 463 , s. n. Ver: Muñoz Rodríguez, J./Guillamón Álvarez, F.J. «Los castellanos y la Guerra de Sucesión: Disciplina social y orden político en la Corona de Castilla (1680-1714)», en Cheiron, 39-40 (2004), 105-128. Muñoz Rodríguez, J. «La sociedad murciana ante la Guerra de Sucesión: crisis política y movilización social «, en Guillamón Álvarez, F.J. el al. La Guerra de Sucesión en los pliegos de cordel, Murcia, 2005, pp. 17-28. Agradezco a la amabilidad del Dr. Muñoz la información de las 3 cartas citadas.

84 AHPM, Prot. 5773, f. 412, 7-7-1706.

85 Poder de J. Benot a Antonio Villalva: AHPM, Prot. 5513, f. 54, 9-4-1707.

86 Declaración de Claudio Therier contra Juan Bta. Basco: AHPM, Prot. 5635, fs. 239-240, 16-12-1706. 
de los franceses. Además de en el comercio intervino, por lo menos indirectamente, en el corso franco-español contra Gran Bretaña que se realizó en la Guerra de Sucesión española ${ }^{87}$, que influyó en que el gobierno de la reina Ana quisiera acabar la lucha cuanto antes, por el daño que recibía. Era considerado mercader de ropas y formaba compañía de comercio con Antonio Fabre, también francés ${ }^{88}$.

Las actividades comerciales de estos franceses de Cartagena, como Baltasar Herau de Olorón, se relacionaban con las de otros franceses de Alicante ${ }^{89}$ y de poblaciones del reino de Murcia como Lorca (Bernardo Bautista Ducós y Juan Honorato Chovet ${ }^{90}$; Antonio Fornalz con Diego Subirant) o Murcia: Claude Barthelón ${ }^{91}$; Diego Ricard, Diego Pastor, Diego Román, Antonio Fabre y Claudio Brunet con Francisco Borrot ${ }^{92}$; Baltasar Herau con Juan Bautista Broc; Antonio Fornalz con Juan Dantoine y Luis Ricard; y también del reino de Granada, como Las Cuevas de Almanzora (Almería).

La penetración de los franceses en la actividad económica de Cartagena volvió a ser importante desde principios del XVIII, pues obtuvieron un cónsul ahora designado por Luis XIV, y eran amparados por el Ayuntamiento de Cartagena, pues se les reclamó el impuesto que se exigía a los comerciantes procedentes de países enemigos, a pesar de lo cual arraigaron en Cartagena.

\section{Malteses, saboyanos, venecianos y suizos}

Una caja de resonancias de los cambios en los grupos extranjeros del comercio de Cartagena fue el nombramiento de cónsules extranjeros, que fue controlado primero por el Consejo de Estado (hasta 1714), después por la Junta de Dependencias y Negocios de la Nación Francesa, llamada luego Junta de Dependencias y Negocios de Extranjeros ${ }^{93}$ y finalmente por la Junta de Comercio, Moneda y Minas ${ }^{94}$. Para aceptar a tales cónsules se exigían unos requisitos, como que los hubiera en el reinado de Carlos II, que no tuvieran cargos públicos nacionales, que se prefiriera al nacional sobre el extranjero y que no ejercieran jurisdicción. El gobernador militar debía informar al Consejo, o luego a la Junta, sobre la idoneidad del aspirante a cónsul, oficio que debió tener atractivo.

87 AMC, Ac.Cap. 27-2-1712.

88 AHPM, Prot. 5636, f. 48, 12-3-1712.

${ }^{89}$ Poderes para cobrar en Vera o Almería: AHPA, Prot. 786, f. 174, 23-7-1720, y 894, f. 216, 10-111721.

90 AHPM, Prot. 5773, f. 118, 28-5-1705.

91 AHPM, Prot. 5771, fs. 700-701, 5-9-1702.

92 AHPM, Prot. 5636, f. 48, 12-3-1712.

93 Crespo Solana, A. «Extranjeros en la corte: análisis de una dialéctica entre la administración borbónica y las comunidades mercantiles en España en la primera mitad del siglo XVIII», en Bravo Lozano, J. ed. Espacios de Poder. Cortes, Ciudades y Villas (Actas del Congreso celebrado en la Residencia de La Cristalera, Universidad Autónoma, Madrid, octubre de 2001), Madrid, 2002, II, pp. 345-362.

94 Castro Martos, M.P. «El Archivo del Consejo de Estado», en Boletín de la ANABAD, 1 (1996), 119138, cfr. 134-136. 
Pedro Pablo Merizano, veneciano, fue designado cónsul de Malta por el Gran Maestre de la Orden o Religión de San Juan, sustituyéndole a su muerte (1707) su sobrino, Bartolomé Mitre, maltés, hijo de César Jacomo Mitre, que se había instalado en Cartagena con Merizano, su cuñado. Bartolomé Mitre, cuyo nombramiento fue aprobado por Felipe $\mathrm{V}$ a propuesta de la Junta de Dependencias de Extranjeros ${ }^{95}$, quien ejerció el comercio en estos años ${ }^{96}$.

La Junta de Dependencias y Negocios de Extranjeros fue la que se ocupó de las propuestas de cónsules de Génova (Julio Antonio Chereguini en Cartagena), Venecia (Pedro Cresafida en Alicante y Cartagena) y Holanda (Pablo Van Halen para Alicante, Cartagena, Mallorca y Valencia) ${ }^{97}$.

Hubo asimismo saboyanos, como Pedro Jay Martínez, y suizos, como Pablo Francisco Dumoulins (Tebay) y Diego Selonf.

\section{Ingleses}

La Guerra de Sucesión afectó enormemente a los comerciantes ingleses, quizá desde el mismo inicio del reinado de Felipe $\mathrm{V}$, pero con más efectividad desde que las tropas inglesas tomaron Gibraltar.

Cuando Manuel Anrich Torres, heredero de los negocios de Anrich Ferrer, se asoció por 6 años al inglés Juan Ellys ${ }^{98}$, no pudo prever que vendría no sólo la guerra de España con Inglaterra, por lo que fueron procesados sus socios Pedro y Bartolomé Fábrega por la Junta de Represalias ${ }^{99}$, sino la ocupación angloholandesa de Cartagena y el triunfo de la causa borbónica en menos de medio año y por lo tanto de los franceses. Ellys había sustituido al también inglés Tomás Moore, al que habían precedido otros a mediados del siglo XVII ${ }^{100}$. Fue una vez recuperada Cartagena por las tropas borbónicas cuando la guerra repercutió en las compañías comerciales de genoveses que, como los hermanos Fábrega y Peragalo, tenían tratos con los ingleses.

\section{EL TRÁFICO EXTERIOR}

La geografía del tráfico exterior realizado a través de Alicante y Cartagena estuvo condicionada en gran parte por la presencia de comerciantes de los diversos

95 AHN, Estado, legajo 611, documento n. 148, consulta n. 128, año 1708.

96 AHPM, Prot. 5774, 31-12-1711.

97 Consultas n. 560, 563 y 564, 1713: AHN, Estado, legajo 612, documentos nn. 7, 20 y 21.

98 Compañía entre Manuel Anrrich y John Ellys: AHPM, Prot. 5181, fs. 455-456, 26-6-1699.

99 AHPM, Prot. 5513, fs. 30 y 55, 9 y 30-11-1705.

100 Maestre de San Juan Pelegrín, F. «La actividad comercial de Alicante y Cartagena. Similitudes, diferencias y comunidades mercantiles (años 1643-1660)", en Espacio, Tiempo y Forma (Hª Moderna), Serie IV, 20 (2007), 95-119. 
territorios que ya se han comentado, que fueron fundamentalmente Francia y los estados de Italia.

\subsection{La exportación de lana, barrilla, sosa y esparto}

Alicante y Cartagena fueron puertos de exportaciones de lana y barrilla en la $2^{a}$ mitad del siglo XVII ${ }^{101}$, situación que se mantuvo entre 1700 y 1750 . El puerto de Cartagena era para los comerciantes un importante punto de acceso al reino de Murcia (en realidad en éste sólo había entonces otro, el pequeño embarcadero de Mazarrón, aunque también se utilizaría alguna vez la ensenada de Águilas ${ }^{102}$ ), no obstante que también servía para llegar al reino de Toledo (Castilla La Mancha y Madrid) y los reinos de Granada y Jaén, con la notable competencia de Alicante y Málaga, que contaban con mayores recursos económicos, poblaciones y grupos mercantiles.

Los Montanaro eran en 1705 exportadores de lana de los reinos de Murcia y Granada, procedente principalmente de Huéscar, donde tenían un administrador que adquiría grandes cantidades en las comarcas próximas, dirigía el lavadero y contrataba los portes, aunque también la exportaban sin lavar. Cuando la lana llegaba a Cartagena los Montanaro la expedían a Venecia (a Francisco Campión y Aurelio y Antonio Barbieri) o Génova (a Juan Bautista Benedicto y Alejandro Cárrega y compañía), para lo que fletaban barcos y previamente pagaban los derechos reales o impuestos y se obligaban a favor del veedor del contrabando a traer certificación (corresponsiva) del destino de la exportación, concertada con comisiones de genoveses (Juan Bautista Ansaldo) ${ }^{103}$.

Durante la Guerra de los Nueve años con Francia, Juan Bautista Montanaro hubo de afrontar varios embargos de los barcos fletados o cargados por él, como el de un navío que fue retenido en Barcelona y del que hubo de pedir que desembargaran lana y barrilla destinadas a Venecia ${ }^{104}$. Pero esto fue sólo una pequeña anécdota, en comparación con los embargos que hubo de sufrir por parte de los franceses. Poco después fue apresado un navío genovés con ropa que J. Cagnoni y Antonio Francisco Magnoni, florentinos, habían cargado en Londres para él, por lo que Montanaro solicitó su devolución alegando que era genovés y por lo tanto neutral; fueron embargadas en Marsella lana y barrilla enviadas a Venecia a Francisco Campión y a los Barberi; y aún fue tomado otro navío con lana y barrilla remitidas a Génova, a los Cárrega y a Juan Jorge Colombo, alegando esta vez para su devolución que era vasallo del rey de España y no genovés ${ }^{105}$.

101 Montojo Montojo, V./Maestre de San Juan Pelegrín, F. «Los comerciantes de Cartagena y su actividad en Huéscar en la segunda mitad del siglo XVII», en Campesinos, Nobles y Mercaderes: Huéscar y el Reino de Granada en los siglos XVI y XVII, Huéscar, pp. 93-110.

102 Francisco Nas protestó letra de cambio contra Rosa y Dupín de Alicante pues estaban empleadas en 576 quintales de barrilla embarcadas en Águilas: AHPA, Prot. 1320, f. 1-2, 2-1-1713.

103 AHPM, Prots. 5378, 5379, 5772 y 5773, passim.

104 Poder de Montanaro a Pablo Dalmases, vecino de Barcelona: AHPM, Prot. 5377, f. 131, 6-9-1691.

105 Montojo Montojo, V./Maestre de San Juan Pelegrín, F. «La actividad...», op. cit., p. 114. 
Por lo tanto, Juan Bautista Montanaro tenía contactos esporádicos en Holanda e Inglaterra, de tal forma que comerciantes de Amsterdam y Londres podían acudir a él para asuntos imprevistos ${ }^{106}$. Pero su comercio era particularmente intenso con Génova y Venecia (Italia), Marsella (Francia), Cataluña, Valencia y Mallorca (Corona de Aragón hasta 1707), el reino de Granada (Vera, el valle de Almanzora, Huéscar y Baza en el interior; Mojácar, Almería, Málaga y Motril por vía marítima), Cádiz y Sevilla.

Cuando acabó la guerra con Francia se le complicaron las cosas: fue denunciado por imputársele que carros con lanas de su lavadero de Huéscar iban sin los documentos legales y unos meses después procedía junto con otros hombres de negocios (Mateo Rizo, Tomás Moore y compañía) contra un auto del corregidor que había fijado el precio de la barrilla en 14 reales cada quintal ${ }^{107}$. Al poco le afectó la quiebra de los Barbieri de Venecia ${ }^{108}$.

Estos embargos realizados por los franceses podrían explicar, entre otras cosas, que los Montanaro tomaran partido por el archiduque Carlos de Austria y no por Felipe $\mathrm{V}$ de Borbón ${ }^{109}$, como lo hicieron otros vecinos de Cartagena en no pequeña cantidad, si la comparamos a las demás poblaciones de los reinos de Murcia y circunvecinos ${ }^{110}$.

Otros exportadores de lana fueron el bearnés Jaime Soler (a Génova para José Rizo), y los italianos Mateo Rizo (a Barcelona o Mataró en 1694 para Juan Lacumba), Bartolomé Fábrega ${ }^{111}$, Juan Andrea y Marcelo Merano (a Génova para Tomás Gamba y Jacome Grondona), y Tomás Pisarelo, vecino de Alicante, para Marsella.

Cartagena mantuvo un menor volumen de comercio que Alicante, lo cual no excluye el interés que señala la acción conjunta de comerciantes de Alicante y Cartagena en diversos negocios, como la exportación de lanas, barrilla, esparto y vino de todo el Sureste, o la explotación de las almadrabas pesqueras. No era infrecuente entre los comerciantes genoveses que tuvieran familiares en uno y otro puerto, como también los franceses Amorrich, exportadores de lana en 17041709 (ver anexo 1).

Los exportadores de lana también expedían barrilla: Montanaro a Venecia o Génova; los franceses (Noel Bartholón, Pedro Olivier y Juan Bautista Rebufat'112) a

106 Obligación de Jerónimo Nicolich, veneciano, a favor de Juan Bta. Montanaro: AHPM, Prot. 5238, fs. $268-269,19-12-1697$.

107 Poder de los hombres de negocios a Juan Martínez Carrasco: AHPM, Prot. 5238, f. 196, 17-10-1697.

108 Poder de Montanaro a Antonio Paganela para pedir embargo de bienes: AHPM, Prot. 5771, f. 507, 24-4-1702.

109 Montojo Montojo, V./Maestre de San Juan Pelegrín, F. La Cofradía de Nuestro Padre Jesús Nazareno (Marrajos) de Cartagena en los siglos XVII y XVIII, Cartagena, 1999, p. 142.

110 León Sanz, V./Sánchez Belén, J.A. «Confiscación de bienes y represión borbónica en la Corona de Castilla a comienzos del siglo XVIII», en Cuadernos de Historia Moderna, 21 (1998), 127-175.

111 AHPM, Prot. 5443, f. 31, 21-1-1672.

112 AHPM, Prot. 5638, fs. 77-79, 7-8-1718. 
Marsella. Adquirían sosa (Claudio Brunet, francés, arrendaba la de los saladares de Cartagena y la exportaba ${ }^{113}$; y también el español Juan González ${ }^{114}$ ) en el reino de Murcia, la gobernación de Orihuela y el reino de Granada, embarcándolos tanto en el litoral murciano (Cartagena, Mazarrón), como en el almeriense (Garrucha, Carboneras), con destino a Italia, (Génova y Venecia) y a Francia (Marsella), pero también a los puertos atlánticos de Andalucía (Cádiz) ${ }^{115}$.

Aunque la barrilla se cultivaba en el campo de Cartagena, como en otras muchas comarcas de los reinos de Granada, Murcia y Valencia, desde finales del siglo XV, su producción creció notoriamente en las décadas primeras del XVIII, de tal forma que los comerciantes hacían grandes acopios de este producto.

Esta proximidad de la producción a los puertos de embarque, a diferencia de la lana, conllevó otros problemas, pues para su adquisición los comerciantes seguían el mismo sistema de adelantos de dinero, en este caso a los labradores o cosecheros, no a los ganaderos. Estos últimos eran grandes propietarios de ganados pero también de tierras, mientras que los cosecheros de barrilla y esparto no lo eran, ni tenían el poder que los ganaderos y comerciantes, muy introducidos en los concejos como alcaldes y regidores.

El Ayuntamiento de Cartagena se convirtió en caja de resonancia de las quejas de los cosecheros contra los precios que les imponían los comerciantes. Ante tales protestas, designó una comisión formada por dos cosecheros y dos comerciantes: frente a los 16 reales por quintal que pedían los últimos, se fijó el precio en $14^{116}$.

La negociación de la adquisición y exportación de barrilla era llevada directamente por los propios comerciantes en lo que se refería al campo de Cartagena (por ejemplo, el francés Claudio Brunet ${ }^{177}$ ), aunque los labradores recurrían a la intervención del Ayuntamiento para evitar los abusos de los comerciantes ${ }^{118}$, pero si estos últimos decidían adquirirla más lejos lo podían hacer muchas veces por medio de apoderados.

Los impuestos que gravaban la producción y exportación de barrilla eran muy importantes para estos comerciantes, que intentaban sacar el mayor beneficio del negocio, de tal manera que a veces eran ellos quienes arrendaban el diezmo eclesiástico sobre la barrilla. Otras eran los grandes propietarios de tierras. En uno u otro caso la renta decimal podía ser objeto de especulación, ya para eximirse y eximir a otros, ya para destinar la producción resultante al comercio. La elevación fiscal favoreció el traslado a Alicante.

Algo muy parecido a la barrilla, en relación a lo que decíamos sobre el apro-

113 AMC, Ac.Cap. 18-6 y 13-8-1712.

114 AMC, Ac.Cap. 21-1-1719.

115 Román Cervantes, C. «Actividad mercantil en una ciudad de la periferia: Cartagena (17131715)», en Cuadernos de Historia Moderna y Contemporánea, 10, 1989-1990, pp. 65-80.

116 AMC, Ac.Cap. 23-10-1700, f. 459r.

117 AMC, Ac.Cap. 20-12-1712.

118 AMC, Ac.Cap. 29-10-1712. 
vechamiento de su fiscalización, sucedía con el vino local. En el campo de Cartagena se producía vino y uva, aunque no en tanta cantidad que permitiese su exportación (o quizá se dedicaba al consumo local por su baja calidad), salvo de forma excepcional (Juan Bautista Montanaro expidió algún cargamento de vino a Hamburgo, seguramente alicantino), a diferencia de Alicante y Málaga, que eran ciudades exportadoras de vino y pasa locales ${ }^{119}$.

Exportaban además aceite del reino de Granada (Almería ${ }^{120}$, Olula del Río ${ }^{121}$ ), o lo destinaban al abasto de Cartagena, procedente de Las Cuevas (Almería) ${ }^{122}$. Y algo parecido se puede decir de los franceses, entre quienes hubo trayectorias comerciales de larga duración en este periodo con este tipo de actividad, como la de Miguel Turón, o la de Sairas y cía. (Honorato y Enrique Sairas y Pedro Martel) ${ }^{123}$, como también lo hacían los de Alicante con pasa de Málaga ${ }^{124}$ y atún de Cádiz ${ }^{125}$ para Italia.

\section{LAS IMPORTACIONES}

Gran parte de la actividad de los comerciantes de Alicante y Cartagena, tanto mayoristas u hombres de negocios, como minoristas, consistió en la introducción de géneros extranjeros, fueran tejidos, ropa, especiería, etc. En realidad, los mercaderes de lonja o mayoristas tenían sólo una parte del gran comercio, pues predominaban los comerciantes que abrían una tienda o dos y las surtían de géneros, formándose así una red de tiendas ${ }^{126}$.

Los genoveses los introducían por comisión de comerciantes de Génova ${ }^{127}$, mientras que los franceses lo hacían de Marsella ${ }^{128}$.

Los comerciantes de Alicante y Cartagena (Nas, Lombardón, Montanaro y Merano ${ }^{129}$, Marco y Antonio Feuvrier ${ }^{130}$ ) proveían de géneros textiles y de dinero a

119 Giménez López, E. Alicante en el siglo XVIII..., op. cit. Quintana Toret, F.J. «El comercio malagueño en el s. XVII», en Pedralbes, 7 (1987), 79-102.

120 Poder de Fco. Rochefort para cobrar a Pedro Laugier: AHPA, Prot. 592, f. 26, 22-7-1715.

121 AHPM, Prot. 5767, fs. 71-73, 10-5-1724; Prot. 5979, fs. 3r-5v, 15-1-1728 y Prot. 5192, fs. 469r470v, 15-11-1744

122 AMC, Ac.Cap. 4-10-1718.

123 AHPM, Prot. 5979, fs. 3r-5v, 15-1-1728 y Prot. 5989, f.52, 10-2-1741.

124 Alejandro Lesbros, José Benit y Alonso Martín: AHPA, Prot. 910, f. 56, 20-3-1710.

125 Pedro Lombardón y José Mª Pereli Burlo, de Cádiz: AHPA, Prot. 441, f. 81, 13-7-1710.

126 Marcos Martín, A. España en los siglos XVI, XVII y XVIII, Barcelona, 2000, p. 675.

127 Como los remitidos desde Génova por Juan Agustín Paganino a Juan Llobregat y Manuel Anrich Torres, que se quedó en Alicante cuando esta ciudad era aún austracista: AHPM, Prot. 5513, fs. 155-157, 4-7-1707.

128 Aceite y jabón, en el navío La Victoria, que debía ser para Claudio Brunet, quien tuvo que pedir que fuera admitido con la certificación que traía del Almirantazgo de Francia por haber perdido la patente de sanidad: AMC, Ac.Cap. 20-12-1712. Este barco, en realidad, había sido cargado con otras mercancías por Gaspar y Nicolás Solicofre, comerciantes de Marsella, para Carlos María Rizo y Agustín Merano, que también pidieron libre entrada para las mercancías: AMC, Ac.Cap. 30-12-1712. Sobre todo introducían tejidos, Claudio Brunet sángalas: AMC, Ac.Cap. 17-10-1713.

${ }_{129}$ AHPM, Prots. 5329, fs. 388 y 509, $20-3$ y 14-8-1700; 5771, fs. 487 y 567-568, 30-3 y 16-5-1702.

130 Obligación de pago de Juan Navarro: AHPM, Prot. 5771, f. 616, 4-7-1702. 
mercaderes de tienda de los reinos de Valencia (Benimagrell $\left.{ }^{131}\right)$, Murcia (Peñas de San Pedro ${ }^{132}$ ) y Granada (Puebla de don Fadrique ${ }^{133}$ ), pero también a particulares $^{134}$, o a los nuevos pobladores del campo de Cartagena ${ }^{135}$, muchas veces al fiado, con lo que ello podía conllevar, pues en 1714 Carlos María Rizo pleiteaba ante la Real Chancillería de Granada contra Juan Chacón y María Buendía, su mujer, por deuda de 235 pesos y 6 reales $^{136}$.

Los suizos Jorge Schirmer y cía. (Dumoulins), representados por Francisco Castañeda y Sebastián Absten, muy vinculados también a los franceses, introducían manufacturas para Honorato Abou y Ausias ${ }^{137}$, franceses de Cartagena y Lorca.

Considerados estos grupos de comerciantes en conjunto, puede decirse que una gran parte de su actividad se realizaba en un contexto de economía de crédito, es decir, mediante ventas al fiado que denotaban una relación de confianza, pues se permitía al comprador diferir todo el pago o una parte de él; relación que a veces no funcionaba y entonces el acreedor debía proceder a facultar a un tercero para que cobrase o en último término a recurrir a la justicia. A partir del análisis de las escrituras de obligación de pago podemos decir que su clientela era fundamentalmente murciana, predominando la del Campo de Cartagena (17 de 43 otorgantes), la de la ciudad (10) y la de Lorca (6), y en número mucho menor, de Mazarrón (3), Murcia (2), Totana (1), Elda (1), Cuevas del Almanzora, en Almería (2), y Orán (1). Cabe observar que la distribución geográfica de esta clientela era parecida a la de los comerciantes de Alicante, que se extendía a los reinos de Valencia y Murcia, en éste a Yecla, Tobarra, Chinchilla y Minaya. En lo que se refiere a los productos negociados en estos contratos, predominaron tejidos, como en Valencia ${ }^{138}$, y otros géneros, término este último en el que se englobaban manufacturas, coloniales (azúcar y cacao) y especiería, así como préstamos.

La introducción de tejidos y coloniales era lo más característico del comercio de importación de los negociantes franceses. La negociación de este tipo de tráfico, que puede estudiarse a través de la correspondencia entre los hermanos Amorrich de Alicante, Cartagena y Marsella (anexo 1) y la partición de bienes de Miguel Turón (1744), se hacía con comerciantes de Lyon, ya directamente (con Zellveguer y Ousgler), ya indirectamente: con Fayola Chaix y cía., por medio de Cairón y cía. de Murcia, y José Casal de Cartagena; o con Domergue Estoren y cía., por medio de José Casal, y con Antonio Olier, por Pedro Verges, también de Cartagena ${ }^{139}$.

131 Francisco Nas: AHPA, Prot. 320, f. 67, 15-4-1713.

132 AHPM, Prot. 5771, f. 4, 4-1-1701.

133 AHPM, Prot. 5771, f. 73, 6-3-1705.

134 Poder de Antonio María Montanaro a Esteban Rizo: AHPM, Prot. 5773, f. 268, 21-11-1705.

135 José Casal a Pedro de Mula, morador del partido de Ferriol: AHPM, Prot. 5767, 2-12-1722.

136 Archivo de la Real Chancillería de Granada (ARChG), 512/2467/10.

137 AHPM, Prot. 5979, fs. 3r-5v, 15-1-1728.

138 Muñoz Navarro, Daniel, «Mercaderes extranjeros y comercio textil de importación en la Valencia deciochesca», Dubert, I., Sobrado Correa, H. eds., El mar en los siglos modernos, Santiago de Compostela, 2009, tomo 1, pp. 469-483.

139 Miguel Turón fue primer diputado de la nación francesa, acusado en 1739 por excesos en ejercitar el oficio de cónsul: AHN, Estado, legajo 606-2, exp. 53. 


\section{CONCLUSIONES}

El comercio de Alicante y Cartagena, aunque mantuvo en la primera mitad del XVIII la exportación de lana y barrilla, pasó a desempeñar fundamentalmente una función receptora de manufacturas procedentes de Francia e Italia y de coloniales (especias americanas). La Guerra de Sucesión incidió en el afrancesamiento del colectivo mercantil, aunque se mantuvo una presencia de genoveses aún importante. Con la introducción de los franceses, el comercio de Levante se incorporó a un tráfico en que predominó la ruta de Marsella y su continuación hacia Génova, Esmirna, Negroponto o Cabo Negro, es decir, inserta plenamente en el Mediterráneo Oriental. Por otra parte, este periodo se caracterizó por la incorporación no sólo de numerosos franceses, sino también de catalanes, venecianos, saboyanos, suizos y malteses. Los comerciantes de ambas ciudades dieron también apoyo logístico a las naves de guerra de España que tuvieron que acudir a las guerras de Italia.

\section{ANEXO 1. Tráfico de mercancías entre Alicante, Cartagena y Marsella por los Amorrich}

\begin{tabular}{|l|l|l|}
\hline \multicolumn{1}{|c|}{ Fecha } & \multicolumn{1}{|c|}{ Recorrido } & \multicolumn{1}{c|}{ Objeto, remitente y destinatario del tráfico } \\
\hline $1704-8-4$ & Marsella-Alicante & barca con Brasil de José Amorrich a Jaime Amorrich \\
\hline $1705-10-31$ & Alicante-Marsella & barca de Jaime Amorrich a Francisco Amorrich \\
\hline $1705-6-14$ & Marsella-Alicante & barca con Brasil de José Amorrich a Jaime Amorrich \\
\hline $1705-7-6$ & Alicante-Marsella & barca con lana de Jaime Amorrich a José Amorrich \\
\hline $1707-3-22$ & Marsella-Cartagena & pingüe con Brasil de José Amorrich a Jaime A. \\
\hline $1707-10-28$ & Marsella-Cartagena & barco con Brasil de José Amorrich a Jaime A. \\
\hline $1707-12-10$ & Marsella-Cartagena & polacra con Brasil para José Amorrich \\
\hline $1707-12-28$ & Marsella-Cartagena & barca con tejidos y Brasil para Jaime Amorrich \\
\hline 1708 & Marsella-Cartagena & barca con tejidos para José Amorrich \\
\hline 1708 & Marsella-Cartagena & barca con tejidos de Cambray para José Amorrich \\
\hline 1708 & Cartagena-Marsella & barca con piastras para Francisco Amorrich \\
\hline $1708-3-i$ & Marsella-Cartagena & barca con tejidos de Francisco a José Amorrich \\
\hline $1708-7-13$ & Marsella-Cartagena & barca con jengibre de José Amorrich a Pierre Beguer \\
\hline 1709 & Cartagena-Marsella & barca con lana de Jacques a Francisco Amorrich \\
\hline 1709 & Marsella-Cartagena & barca con Brasil para Jaime Amorrich \\
\hline $1709-4-15$ & Cartagena-Marsella & barca con lana de Jaime a José Amorrich \\
\hline $1709-6-12$ & Marsella-Alicante & barca con palo Brasil de José a Francisco Amorrich \\
\hline $1709-6-28$ & Cartagena-Marsella & barca con piastras de José a Francisco Amorrich \\
\hline $1709 ?$ & Marsella-Cartagena & barco con cacao de Francisco a José Amorrich \\
\hline
\end{tabular}

FUENTE: Archivo Municipal de Alicante, Papeles de comercio, 2-19-34. 